\title{
O LIMITE DA NORMATIVIDADE NA TEORIA POLÍTICA DE ERNESTO LACLAU
}

Daniel de Mendonça

A obra de Ernesto Laclau, principalmente após o lançamento de Hegemony and socialist strategy, em colaboração com Chantal Mouffe, tem sido um esforço teórico no sentido de apresentar uma interpretação acerca do político como âmbito específico e explicativo das relações sociais (cf. Laclau e Mouffe, 1985). Apesar de seu trabalho por vezes ser "acusado" de abstrato, filosófico, numa palavra, "despreocupado" com as práticas políticas cotidianas, não é esse em absoluto o objetivo do autor. Pelo contrário, Laclau autodenomina-se um "teórico político", no sentido de que todo o seu esforço intelectual tenha uma aplicabilidade analítica e normativa no campo da política.

O presente artigo resulta num exercício no sentido de pensar o terreno da normatividade no âmbito da teoria política, tendo como pressuposto a ontologia presente na teoria do discurso laclauniana. Partimos da premissa, como já afirmamos, de que o autor, na condição de teórico político (e não de filósofo político), visa a apresentar uma teoria política que tenha aplicabilidade analítica, mas que também seja útil no momento de se pensar normativamente. 
Defendemos que o plano da normatividade, levando-se em conta essa perspectiva teórica, depende inexoravelmente da concepção de ontologia política elaborada pelo autor, a qual terá seus principais pressupostos e elementos explorados neste artigo.

Para a consecução desse objetivo geral, primeiramente abordaremos a posição pós-fundacionalista defendida pelo autor. Na sequência, apresentaremos Laclau como um teórico e não como um filósofo político. A seguir, analisaremos as noções de ideologia e discurso, centrais para a ontologia política da teoria do discurso. Depois discorreremos sobre antagonismo e deslocamento, categorias explicativas da incompletude de sentidos sociais, conforme a visão do autor. Finalmente, tendo em vista os pressupostos ontológicos apresentados, buscaremos estabelecer as possibilidades e os limites da normatividade tendo em vista a teoria do discurso.

\section{$136 \quad$ Laclau e o pós-fundacionalismo}

Um ponto de partida razoável para a compreensão da obra de Laclau, mas certamente não o único, reside na compreensão de que o seu esforço teórico está filiado a uma matriz pós-fundacionalista. O pós-fundacionalismo consiste numa constante interrogação crítica em direção aos projetos teóricos que visam se estruturar a partir de um fundamento último, como se tal fundamento fosse subjacente às próprias práticas políticas stricto sensu, como, por exemplo, o essencialismo econômico em última instância presente na tradição marxista (Laclau e Mouffe, 1985). Apesar de o pós-fundacionalismo ser a crítica a um fundamento em última instância que explicaria e fecharia todos os sentidos numa totalidade chamada de sociedade, conforme Marchart (2007, p. 2), ele

[...] não deve ser confundido com antifundacionalismo [...], uma vez que a abordagem pós-fundacional não visa a apagar 
completamente as figuras do fundamento, mas enfraquecer o seu status ontológico. O enfraquecimento ontológico do fundamento não conduz ao pressuposto da completa ausência de todos os fundamentos, mas antes ao pressuposto da impossibilidade de um fundamento final, o que é algo completamente diferente, já que implica uma maior consciência de, por um lado, a contingência e, por outro lado, o político, como o momento do parcial e sempre, em última instância, fundamento sem sucesso ${ }^{1}$.

Tendo em vista esse pressuposto pós-fundacionalista, Laclau estrutura a sua noção do político a partir da constatação de que as próprias relações políticas são sempre instáveis e contaminadas pelo antagonismo, pela precariedade e pela contingência. Nesse sentido, quaisquer esforços normativos que busquem a priori estabelecer cenários futuros de emancipação ou de prescrição acerca da melhor forma de tomada de decisões públicas, tais como a tradição marxista e as teorias deliberativas, são alvos constantes de crítica do teórico argentino.

Como uma teoria pós-fundacionalista da política, o intento intelectual do autor é demonstrar que qualquer fundamento político ou de teoria política será sempre provisório e dependente das condições efetivas de sua inscrição. É nesse sentido que a noção de hegemonia ganha centralidade na perspectiva Laclau, pois esse conceito tem a capacidade de, ao mesmo tempo, ser uma importante ferramenta de análise do social e também de prescrição normativa, uma vez que tal noção pressupõe justamente a constante instabilidade das relações políticas concretas (no plano ôntico) e das sempre precárias tentativas de normatizar a "boa política".

\footnotetext{
1 Todas as citações de trechos de textos originalmente escritos em línguas estrangeiras (inglês e espanhol) foram traduzidas livremente pelo autor para uso exclusivo neste artigo.
} 
Todo fundamento político estrutura-se discursivamente quando se hegemoniza, ou seja, quando determinada posição política particular passa a representar os mais variados setores da sociedade. Assim, a hegemonia é o momento da decisão política, da sedimentação de determinado discurso. Contudo, dada a instabilidade ontológica do político, ou seja, a eterna contaminação do plano ôntico pelo ontológico, toda hegemonia pressupõe uma contra-hegemonia e ambas só podem ser conhecidas no momento em que essas práticas políticas surgem como tais.

Para Laclau, dessa forma, a instabilidade constante nas relações políticas reais não pode ser percebida como algo abstrato. O autor é absolutamente consciente de que o seu projeto teórico o é no sentido mais estrito do termo, ou seja, toda a estrutura do seu pensamento visa à aplicação, no mínimo, no plano da análise política. Dessa forma, entendemos que, para Laclau, qualquer proposta normativa, que

138 não leve em consideração os elementos pós-fundacionalistas apresentados, tem valor teórico-científico restrito.

\section{Laclau: um teórico político}

Laclau transita entre a teoria política e a política com um objetivo muito preciso: seu pensamento não está inscrito num campo eminentemente filosófico, visto que o mesmo tem uma preocupação de análise do social, de ser uma ferramenta teórica de aplicação. Essa impressão é compartilhada por Oliver Marchart (2008, p. 77).

No marco de uma conferência sobre desconstrução e pragmatismo, Ernesto Laclau iniciou sua intervenção recordando-nos que estava ali "como teórico político antes de filósofo no sentido estrito do termo" (Laclau, 1996, p. 47). Laclau não nos disse como seria um filósofo "no sentido estrito do termo", mas presumimos que busca diferenciar seu projeto - que se ocupa exclusivamente de questões 
de política e teoria política - da prática de fazer filosofia "pura", ou seja, no sentido de uma disciplina acadêmica ou na flutuação livre do raciocínio metafísico sem nenhum campo de aplicação particular.

Laclau, em entrevistas, percebe claramente que sua teoria política não pode ser desvinculada da sua própria prática como ativista social, ou seja, seu pensamento tem efetivamente um viés normativo de uma teoria política radical. Citamos, a seguir, dois trechos extraídos de duas entrevistas publicadas em Nuevas reflexiones sobre la revolución de nuestro tiempo (doravante NR). O primeiro retrata claramente o ponto em que o autor destaca a leitura dos fenômenos sociopolíticos a partir de duas categorias centrais ao seu aporte teórico, articulação e hegemonia.

A ideia da política como hegemonia e articulação, por exemplo, é algo que tem acompanhado a minha trajetória política. Recordo que, em 1984, depois de muitos anos, viajei a Buenos Aires com Chantal Mouffe e consultamos velhos trabalhos meus. Chantal se surpreendeu ao ler os meus editorais de Lucha Obrera (do qual eu havia sido diretor), de vinte anos antes, nos quais a luta socialista já se colocava em termos de hegemonização das tarefas democráticas por parte da classe operária (Laclau, 1993, p. 188).

O segundo trecho revela de forma ainda mais evidente a relação íntima entre a sua teoria e os próprios fenômenos que ela propõe iluminar.

Por isso é que eu não tive de esperar para ler os textos pósestruturalistas para entender o que é uma "articulação" [...], um "significante flutuante" ou a metafísica da presença: aprendi através da minha experiência prática de ativista em Buenos Aires. Por isso, quando hoje leio Gramatologia, $S / Z$ 
ou os Escritos de Lacan, os exemplos que me vêm sempre à mente não são de textos filosóficos ou literários, são os de uma discussão em um sindicato argentino, o choque de slogans opostos em uma manifestação ou de um debate de um congresso partidário (Laclau, 1993, p. 210).

A partir dos dois trechos acima reproduzidos, fica evidente que, para o autor, sua tarefa como teórico não é a de ser um "filósofo político no sentido estrito do termo", mas a de produzir uma teoria que explique os fenômenos sociopolíticos e que, ao mesmo tempo, indique meios para transformações sociais. Não há, portanto, uma separação estrita entre teoria e prática política. O empreendimento do autor, nesse sentido, reveste-se de uma dupla função: explicativa e normativa.

O sentido explicativo de seu esforço teórico é mais evidente à primeira vista pela leitura dos seus textos. Laclau comumente apresenta suas categorias analíticas e as ilustra 140 a partir de eventos políticos. Essa operação visa à elucidação das noções por ele empregadas - muitas vezes tidas por seus leitores como abstratas - e, ao mesmo tempo, ao seu interesse de demonstrar o poder explicativo das mesmas. Outro elemento que é importante para a compreensão da estrutura explicativa do autor é o fato de que a própria compreensão de suas categorias só é efetivamente possível se a estrutura que as abriga for também conhecida. Por exemplo, para a compreensão de uma noção tão central para a sua teoria como a de hegemonia, é preciso saber como a mesma é operada a partir de uma série de outras noções tais como elementos, momentos, articulação, pontos nodais, antagonismo, para citar as mais recorrentes empregadas pelo autor.

O aspecto normativo não parece, num primeiro momento, tão evidente a partir da leitura dos seus trabalhos. A chave para a compreensão do mesmo está justamente na percepção de que as dimensões teóricas e práticas são 
indissociáveis para ele. Na introdução de uma coletânea de textos, cujos autores utilizam sua estrutura teórica em análises empíricas, Laclau, após estabelecer que a separação entre teoria política e prática política é uma "operação artificial", afirmou taxativamente que "como as categorias teórico-políticas não existem apenas nos livros, mas são também partes de discursos que de fato informam instituições e relações sociais, essas operações desconstrutivistas são parte integral do fazer da vida política” (Laclau, 1994, p. 2). Isso quer dizer que é papel da teoria política, pelo menos este é assim assumido por Laclau, que ela deva ser explicativa, mas que também aponte uma linha normativa, uma verdadeira tarefa de um ativista intelectual.

Acreditamos ser ainda importante mencionar que o normativo da teoria do discurso depende da estrutura de explicação dos fenômenos sociopolíticos construída pelo autor. Nesse sentido, o normativo não é um normativo ideal, vinculado a uma situação hipotética, dificilmente realizável ou ainda irrealizável. Trata-se de um normativo limitado por constraints estruturais, porém passível de ser desejado. Em um conhecido ensaio publicado com Chantal Mouffe, "Posmarxismo sin pedido de disculpas", respondendo a um conjunto de críticas desferidas por parte de intelectuais marxistas contra a obra Hegemony and socialist strategy (doravante HSS), nesse caso em particular, Norman Geras, eles enfocam a possibilidade e o lugar do normativo:

Estamos vivendo, pelo contrário, um dos momentos mais excitantes do século XX: o momento em que novas gerações, sem os prejuízos do passado, sem teorias que se apresentavam como "verdades absolutas" da história, estão construindo novos discursos emancipatórios, mais humanos, diversificados e democráticos. As ambições escatológicas são mais modestas, mas as aspirações de libertação são mais amplas e profundas (Laclau e Mouffe, 1993, p. 112). 
Efetivamente a crítica centra-se, nessa passagem, sobretudo em relação à teoria marxista, entendida por Laclau como essencialista e objetivista. Essencialista no sentido de que o determinismo econômico é entendido por essa tradição, em última instância, como uma verdade a priori e uma característica necessária a todo tipo de formação social. Objetivista, no sentido de que, para Laclau, o marxismo não observa um elemento ontológico social fundamental: a impossibilidade de, em última instância, ser alcançada a objetividade. O "objetivo" é quando se acredita que o objeto é passível de ser plenamente constituído. Para o autor, a essência e o objetivo são impossíveis de ser alcançados e toda a teoria política e social que postular tais buscas terá o seu conteúdo normativo prejudicado. O que queremos dizer por conteúdo normativo prejudicado tem a ver com o que há pouco chamamos de normativismo ideal, ou seja, praticamente ou mesmo impossível de ser realizado. Assim, 142 pensar normativamente tendo como inspiração epistemológica o pós-estruturalismo laclauniano é considerar a ocorrência de acontecimentos políticos efetivos, movimentos políticos reais ${ }^{2}$.

É nesse sentido que as ambições escatológicas da teoria e da prática políticas devem ser vistas de forma mais modesta, uma vez que não há efetivamente uma humanidade a ser libertada no sentido da emancipação humana marxiana. No entanto, e paradoxalmente, as aspirações de libertação são mais amplas e profundas, pois que se abre um leque pratica-

\footnotetext{
${ }^{2}$ Essa é justamente a tarefa normativa empreendida por Aletta Norval (2007, pp. 61-62), em muito inspirada na obra de Ernesto Laclau: "o objetivo deste exercício, embora teórico, não é produzir uma abordagem do discurso democrático que esteja abstraída do 'fluxo da vida' e removida de todo e cada contexto. Não está aqui pressuposto que as gramáticas políticas em geral e as formas democráticas de argumentação em particular poderiam ou deveriam ser abstraídas de contextos ordinários e de interesses e de paixões que inspiram o engajamento na política democrática em primeira instância. Esse desejo de separar a política das preocupações do ordinário geralmente provém de uma negação platônica da retórica e de uma valorização excessiva das reivindicações da razão".
} 
mente infinito de lutas políticas que podem legitimamente reivindicarem-se hegemônicas, ou seja, ocuparem o espaço sempre precário e contingente da representação política de identidades que se articulam entre si em contraposição a um polo opressor comum. Não há, portanto, a necessária proeminência da liderança moral ou política de nenhum grupo, estrato ou classe social, o que redunda na criação de condições muito mais livres para a ação identitária. No ensaio "Más allá de la emancipación”, publicado posteriormente a "Posmarxismo sin pedido de disculpas", Laclau é ainda mais claro quanto ao fato de estarmos vivendo num momento teórico e político diverso das grandes narrativas escatológicas da modernidade.

As lutas sociais contemporâneas deixam plenamente visível esse movimento contraditório que tanto o discurso das escatologias religiosas como o das modernas escatologias seculares ocultaram e reprimiram. Hoje começamos a aceitar a nossa própria finitude, com todas as possibilidades políticas que ela abre. Esse é o ponto em que se apresenta o potencial liberador de nossa era pós-moderna. Poderíamos dizer talvez que hoje estamos no fim da emancipação e no início da liberdade (Laclau, 1996, p. 38).

Esse é um ponto decisivo para a compreensão de Ernesto Laclau como um teórico político. Sua teoria, pelo fato de pressupor que a dinâmica do social percorre caminhos indecidíveis - não passíveis, portanto, de ser domesticados por fórmulas normativas que buscam congelar uma situação ideal, mas pouco provável ou improvável de ocorrer -, os mesmos não podem ser minimamente definidos $a$ priori por qualquer fórmula política normativa.

Diante desse quadro, o papel da teoria, primeiramente, é o de conhecer os elementos ontológicos do político, ou seja, promover uma reflexão do ser enquanto ser. Essa reflexão per- 
passa o conhecimento do discurso como categoria ontológica central. Entender como o discurso é articulado, como sua existência é precária e contingente, ajuda-nos compreender o porquê são inócuas as formulações normativas que visam congelar o fluxo inconstante da vida e das relações sociais.

\section{Ideologia e discurso}

Muito se fala sobre vivermos em uma era que marca o fim das ideologias e, nesse sentido, falar acerca do ideológico parece propor uma discussão um tanto fora de lugar. Contudo, isso depende de como definimos ideologia. Se acreditarmos que ideologia se constitui em falsa consciência (ou consciência alienada), no sentido do marxismo clássico, certamente estaríamos tratando de uma noção ultrapassada. Se, por outro lado, partirmos de um topos próprio do século XX de que, no Ocidente, havia duas ideologias hegemônicas, a capitalista (direita) e a socialista (esquer$144 \mathrm{da}$ ), e acreditarmos que estamos diante de modelos políticos estanques ou, ainda mais grave, trans-históricos, também estaríamos fatalmente incorrendo num erro analítico. Sob tal perspectiva, o problema maior que identificamos nos estudos políticos, quando muitas vezes os autores estão diante da necessidade de definir o termo ideologia, é que eles o fazem não a partir de sua especificidade conceitual ou, como diria Max Weber, a partir de um tipo ideal, mas tendo em vista os casos concretos que analisam. Falham, muitas vezes, porque tomam o aspecto ôntico das ideologias concretas no mesmo patamar ontológico da ideologia como noção, o que é um erro teórico importante. Importante, tendo em vista que a prática de determinado grupo político, dotado de certa ideologia, não pode necessariamente ditar todos os comportamentos políticos futuros de outros grupos, pois cada experiência política ôntica tem a sua própria particularidade que depende de um contexto histórico, precário e contingente. 
Os sujeitos assumem posições ideológicas que guiam suas condutas. Assim, quando consideramos grupos políticos com ideologias determinadas, estamos diante da ideologia num nível ôntico. Contudo, o nível ôntico não determina em si o nível ontológico. Isso quer dizer que não podemos tomar uma ideologia concreta para definir a ideologia, que não podemos tomar o efeito pela causa, que não podemos tomar, por fim, o ôntico para definirmos o ontológico.

Nosso esforço inicial está em dizer que, a exemplo de Althusser (1985), a ideologia não tem uma história, por ela própria ser onipresente e trans-histórica. Para Althusser, "a ideologia é eterna” (1985, p. 85). Assim, entendemos que a ideologia não tem propriamente um final. Somos seres ideológicos e simbólicos por natureza, o que nos permite admitir dois fatos: primeiro, em termos gerais (nível ontológico), sempre haverá ideologia; e segundo, em termos concretos (nível ôntico), as ideologias nascem, sofrem variações e morrem. A noção de ideologia da teoria do discurso de Ernesto Laclau (Laclau e Mouffe, 1985; Laclau, 1993), articula, ao mesmo tempo, os dois fatos acima apontados. Nas palavras de Laclau (1993, p. 106):

O ideológico consistiria naquelas formas discursivas através das quais a sociedade trata de instituir-se sobre a base do fechamento, da fixação de sentido, do não reconhecimento do jogo infinito das diferenças. O ideológico seria a vontade de "totalidade" de todo discurso totalizante. E na medida em que o social é impossível sem certa fixação de sentido, sem o discurso do fechamento, o ideológico deve ser visto como constitutivo do social. O social só existe como o intento vão de instituir esse objeto impossível: a sociedade. A utopia é a essência de toda comunicação e de toda a prática social.

O excerto acima nos leva diretamente à discussão estabelecida na seção anterior, ou seja, sobre a impossibilidade 
de uma mínima previsibilidade normativa em termos de uma forma mais apropriada de solução de questões sociopolíticas. Tal forma de normatividade busca controlar situações que são, na verdade, incontroláveis, visto que estamos ontologicamente, nos termos da teoria do discurso, diante de um social cujos sentidos não podem tornar-se objetivos, ou seja, discursivamente completos, transparentes para a compreensão e para as suas próprias ações como sujeitos ou grupos políticos. Toda a tentativa de fixação de sentidos, de promoção de sua sutura final, é sempre vã, impossível. É exatamente nesse aspecto que Laclau fala sobre a "impossibilidade da sociedade" (Laclau, 1993, p. 104).

No entanto, apesar de impossível a fixação de sentidos identitários (em termos de se poder alcançar uma sutura final), ela é, ao mesmo tempo, paradoxalmente, necessária. Sua necessidade advém do fato de que a ideologia política guarda em si essa "vontade de "totalidade'". Assim, 146 é próprio do discurso político, pois imbuído de ideologia, a busca da conformação do social para a sua própria visão de mundo. A razão é a seguinte: como existe uma "certeza ideológica" sobre qual a melhor forma de política a seguir (mesmo que momentânea) - o que Laclau chama no excerto acima de "discurso do fechamento" - a tarefa político-discursiva de um partido, numa democracia, por exemplo, é a de buscar hegemonizar a sua própria visão de sociedade no agonismo eleitoral. Como vivemos democraticamente, ou seja, pressupondo uma série de ideologias concorrentes, não há como uma delas promover o fechamento completo de sentidos, o que o autor chama de a impossibilidade de fixação de sentidos. Como já dissemos, ao mesmo tempo que é impossível tal fixação, essa é igualmente necessária por um motivo adicional: o estabelecimento de determinada visão ideológica num espaço político democrático é fundamental para que haja ordem, para que exista governabilidade. 
Dessa forma, ideologias, no plano ôntico, ou seja, ligadas à prática política cotidiana são sempre precárias e contingentes, ameaçadas por ideologias contrárias. Já, no plano ontológico, a ideologia, no sentido althusseriano, é omnipresente e trans-histórica, ou seja, numa palavra, eterna. Isso quer dizer que, se não podemos viver sem a presença da ideologia, toda e qualquer tentativa de eliminá-la será sempre vã, interpretando-se que isso não passará tão somente de apenas mais uma ideologia em particular.

Em termos analíticos, conforme Laclau (1993, 2000), a noção de ideologia deve ser entendida a partir da ideia de falsa representação. No entanto, isso não significa que tal ideia marque um retorno ao marxismo, pois isso representaria uma contradictio in adjecto. Na concepção ideológica marxiana, a ideologia é necessariamente o oposto da verdade, uma inversão semântica acerca as relações realmente existentes num contexto societário ${ }^{3}$. Tal concepção pressupõe que a inversão de sentidos produzida pelo fenômeno ideológico oblitera o alcance da verdade, da transparência, da visão não invertida.

Assim, para Laclau (1993, 2000), manter viva a ideia de falsa representação para explicar o fenômeno ideológico significa dizer que não há nada inverídico para se tornar verídico, pois o que deve ser abandonado, nesse particular, é a própria concepção de que há uma verdade absoluta a ser alcançada que seja contrária às inúmeras falsidades que a escondem. Não é a partir desse prisma que Laclau sugere o entendimento do enfoque ideológico. Essa renúncia do par verdade/inverdade é, no entanto, uma renúncia meramente analítica, ou seja, temos de admiti-la porque partimos do pres-

\footnotetext{
${ }^{3}$ Este trecho da ideologia exemplifica o ponto que estou discutindo: "e se em toda a ideologia os homens e as suas relações nos surgem invertidos tal como acontece numa câmera obscura, isto é apenas o resultado do seu processo de vida histórico, do mesmo modo que a imagem invertida dos objetos que se forma na retina é uma consequência do seu processo de vida diretamente físico" (Marx e Engels, s/d, pp. 25-26).
} 
suposto de que não existem sentidos que possam se tornar objetivos, ou seja, ossificados para a eternidade. Para o autor, vivemos numa eterna guerra de interpretações como um pressuposto ontológico do social. É com esse viés que a verdade ou o sentido não distorcido não serão alcançados jamais.

Dissemos que a referida renúncia se dá no plano analítico, pois no plano da disputa política os sujeitos percebem e agem a partir de suas visões ideológicas (distorcidas) como se fossem verdades. É, nesse sentido, que a falsa consciência não deve ser abandonada, uma vez que a distorção do mundo é constitutiva da objetividade social. Isso ocorre, pois há uma renúncia identitária em relação ao reconhecimento do não fechamento de sentidos sociais, plasmados na impossível e, ao mesmo tempo, necessária tentativa de objetivação do mundo ${ }^{4}$. Estamos diante de uma "distorção constitutiva”. O autor estabelece que:

148 O que se trata, contudo, é de uma distorção constitutiva. Quer dizer que estamos postulando um sentido originário (porque este é requerido por toda a distorção) e negando-o (porque a distorção é constitutiva). Nesse caso, a única possibilidade lógica de manter essas duas dimensões aparentemente antinômicas é se o sentido original é ilusório e a operação distorcida consiste precisamente em criar essa ilusão - ou seja, projetar, em algo que é essencialmente dividido, a ilusão de uma plenitude e autotransparência que estão ausentes (Laclau, 2000, p. 17).

\footnotetext{
${ }^{4}$ A concepção de ideologia de Zizek (2005, pp. 46-47) é semelhante: "Esta é provavelmente a dimensão fundamental da 'ideologia': a ideologia não é simplesmente uma 'falsa consciência', uma representação ilusória da realidade; é a própria realidade que deve ser concebida como 'ideológica' - 'ideológica' é uma realidade social cuja existência implica o não reconhecimento de seus participantes no que se refere à sua essência - ou seja, a efetividade social, cuja mesma reprodução implica que os indivíduos 'não separam o que estão fazendo'. 'Ideológica não é a 'falsa consciência' de um ser (social) mas este ser na medida em que sustentado pela 'falsa consciência”".
} 
A ideologia é materializada no discurso. Discurso, por sua vez, não deve ser entendido como o simples reflexo de conjuntos de textos ou de falas, numa dimensão meramente linguística. Discurso é uma categoria que une palavras e ações, que tem natureza material e não mental e/ou ideal. Discurso é prática - daí a ideia de prática discursiva - uma vez que quaisquer ações empreendidas por sujeitos, identidades, grupos sociais são ações significativas. O social, portanto, é um social significativo, simbólico, sobredeterminado. Não aparece como algo a ser desvendado, desvelado - como se fosse possível alcançar a verdade na sua forma mais transparente e final -, mas compreendido, a partir de sua miríade de formas, das várias possibilidades de se alcançar múltiplas certezas, note-se, sempre contingentes e precárias. Assim, o real, como possibilidade de ser perscrutado, conhecido verdadeiramente, como uma positividade transparente, é uma impossibilidade, tendo em vista que esse é significado de diversas maneiras, a partir das lentes sobredeterminadas ${ }^{5}$ dos sujeitos. Essa concepção de tomar o real de múltiplas formas está na base da crítica que Laclau constrói ao marxismo, tendo em vista este último constituir-se não em uma teoria da sobredeterminação do social, mas numa empreitada teórica que, no limite, embasa as relações sociais a partir de uma determinação evolucionista e econômica em última instância, simplificando-as ${ }^{6}$.

\footnotetext{
${ }^{5}$ A sobredeterminação é um termo oriundo da psicanálise, principalmente freudiana, que designa "a pluralidade de determinados fatores que geram um dado efeito final" (Zimerman, 2001, p. 392). Este autor afirma ainda que "a sobredeterminação é o efeito do trabalho de dois mecanismos: o da condensação (que agrupa os diversos fatores como se fossem um só) e o do deslocamento (que pode dar um aparente relevo maior a um fator insignificante, devido a que o fator mais relevante ficou deslocado naquele)" (p. 392).

${ }^{6}$ A ideia da determinação econômica em última instância, cara ao marxismo, é a principal crítica que Laclau opõe à teoria althusseriana, mesmo considerando o fato de Althusser ter incorporado ao seu projeto teórico a categoria freudiana da sobredeterminação, o que seria uma forma de ampliar a possibilidade analítica da teoria marxista. Contudo, essa categoria perde seu potencial heurístico no momento em que o estruturalista francês não rompe definitivamente com o dogma marxista da determinação econômica em última instância.
} 
Sumariamente, apresentamos a natureza material e não ideal de um discurso ${ }^{7}$. No entanto, para fins deste artigo, importa responder a seguinte questão: por que o discurso deve ser percebido a partir de uma dimensão ontológica? ${ }^{8}$ Simplesmente porque ele nomeia o ser da existência, uma vez que a existência necessita necessariamente de uma série de relações simbólicas para alcançar o status de ser e isso somente é possível a partir de uma articulação discursiva. "O que se nega não é a existência dos objetos, externa ao pensamento, mas a afirmação diferente de que os mesmos possam se constituir como objetos à margem de toda condição discursiva de emergência” (Laclau e Mouffe, 1985, p. 108).

Detenhamo-nos um pouco mais nesse ponto para buscar esclarecer a diferença entre existência e ser no âmbito desta discussão. Tal distinção é crucial, pois indica que ao mesmo tempo que Laclau visa distanciar seu aporte teórico de uma dimensão idealista, como dissemos há pouco, ele busca tam150 bém diferenciar seu pensamento de uma dimensão estritamente realista. Conforme essa visão filosófica, o realismo não é redutível à ideologia, sendo a "realidade 'o modo de ser das coisas enquanto existem fora da mente humana ou independentemente desta'" (Portinaro, 2007, pp. 17-18; grifo no original) ${ }^{9}$.

O discurso tem efetivamente uma dimensão realista, marcada, na linguagem de Laclau, pela noção de existência. A existência indica a realidade material das coisas, dos objetos.

\footnotetext{
${ }^{7}$ Este ponto específico a respeito da materialidade discursiva já foi discutido em uma série de trabalhos. Do próprio autor, ver, por exemplo, o ensaio "Posmarxismo sin pedido de disculpas", escrito conjuntamente com Chantal Mouffe (Laclau e Mouffe, 1993). Trabalhos adicionais que discutem direta ou indiretamente o tema podem ser encontrados em duas coletâneas dedicadas ao pensamento do autor (Rodrigues e Mendonça, 2006; Mendonça e Rodrigues, 2008).

${ }^{8}$ Laclau é absolutamente claro sobre o caráter ontológico do discurso: "O discurso é, a partir de nossa perspectiva, o campo de uma ontologia geral, quer dizer, de uma reflexão acerca do ser enquanto ser" (Laclau, 2008a, p. 189; grifo no original).

9 A noção de realidade é enunciada para estabelecer a contraposição com a corrente idealista, ou seja, como se sabe, a discussão central do realismo é com a perspectiva filosófica do idealismo, debate ao qual não interessa para os propósitos deste texto.
} 
Entretanto, a mera existência, por si só, não tem a capacidade de explicar o próprio ser; este, portanto, não se esgota, não pode ser compreendido tão- somente a partir da sua dimensão realista. Assim, devemos entender que a existência só tem um ser se a mesma estiver imersa numa dimensão simbólica, discursiva. E ela sempre está. Em termos políticos, a dimensão discursiva é polêmica, uma luta simbólica para estabelecer o ser da existência. Um exemplo simples dado por Laclau e Mouffe (1993, pp. 114-15), auxiliará na compreensão da relação existência/ser presente no discurso:

Voltando agora ao termo "discurso", o usamos para sublinhar o fato de que toda configuração social é uma configuração significativa. Se chuto um objeto esférico na rua ou se chuto uma bola numa partida de futebol, o fato físico é o mesmo, mas seu significado é diferente. O objeto é uma bola de futebol somente na medida em que ele estabelece um sistema de relações com outros objetos e essas relações não estão dadas pela mera referência material dos objetos, mas que são, pelo contrário, socialmente construídas. Esse conjunto sistemático de relações é o que chamamos discurso.

Dessa forma, os objetos têm, além da dimensão real (existência), a dimensão significativa (ser) e ambas são partes constituintes e inseparáveis do discurso. O real não é realizável por si, mas prescinde de objetivações discursivas (tentativas de fechamento de sentidos, de fixações conceituais). Fora do contexto discursivo, os objetos não têm ser, somente existência (Laclau, 1993). No entanto, como vimos, ainda mais considerando a dimensão política, esses sentidos não são passíveis de ser fechados. A fixação completa de sentidos constantemente nos escapa; está sempre além de nosso alcance. Duas razões fundamentais explicam a inconstância de sentidos, antagonismo e deslocamento. Passamos a analisá-las. 


\section{Antagonismo e deslocamento}

Para a compreensão da lógica antagônica, é preciso, primeiramente, compreender em que contexto a noção de antagonismo é elaborada por Laclau e Mouffe (1985) em HSS. O objetivo central dos autores é o de demonstrar que as relações políticas não se constroem a partir de lutas entre identidades prontas. Mais especificamente: os autores entendem que não podemos considerar identidades políticas num sentido essencialista, ou seja, previamente constituídas antes da própria relação antagônica. $\mathrm{O}$ antagonismo, antes de ser uma relação entre objetividades já dadas, representa o próprio momento em que as mesmas passam a ser constituídas. Assim, antagonismo é condição de possibilidade para a formação de identidades políticas e não meramente um campo de batalha que se forma entre duas forças já prontas.

Laclau e Mouffe exemplificam a lógica antagônica com

152 o exemplo de um proprietário que expulsa os camponeses da sua terra. Nesse momento, estabelece-se uma relação antagônica uma vez que o proprietário, a partir da ação da expulsão, impede que o camponês seja plenamente camponês (ele passa a constituir-se num camponês sem terra). Assim, quando estamos diante de uma lógica antagônica, não estamos diante de identidades pré-constituídas, mas daquelas que têm suas próprias constituições negadas, tendo em vista que a presença do outro é identificada como a condição da impossibilidade da plena constituição. Segundo os próprios autores: "é porque um camponês não pode ser um camponês que um antagonismo existe com o proprietário expulsando-o da sua terra [...]. Na medida em que há antagonismo, eu não posso ser uma completa presença de mim mesmo" (Laclau e Mouffe, 1985, p. 125). Antagonismo é, portanto, uma experiência de negatividade, uma relação que apresenta o limite da objetividade ou da constituição plena das identidades. Nesse aspecto, David Howarth (2000, p. 106) é claro: 
A mera existência de antagonismos confirma que não há leis necessárias na história e não há agentes políticos universais motivados por interesses e identidades préconstituídas. Ao invés disso, os antagonismos introduzem experiências sociais, tais como "fracasso", "negatividade" ou "falta", as quais não podem ser explicadas por nenhuma lógica de sociedade positiva ou essencialista. Eles revelam também a contingência e a precariedade de toda identidade e objetividade social, uma vez que toda identidade está sempre ameaçada por alguma coisa externa a ela.

Considerando que a teoria do discurso parte do pressuposto de que discursos são constituídos antagonicamente, ou seja, a partir da ameaça real oriunda de outros discursos, vejamos mais detidamente ainda a forma como Laclau e Mouffe trabalham o conceito de antagonismo em HSS. Antagonismo é apresentado a partir da sua diferenciação teórico-analítica em relação às noções de "oposição real" (real opposition) e "contradição lógica" (logical contradiction), apresentadas por Lucio Colletti (1975), num esforço deste autor para iluminar tais categorias kantianas.

Assim, segundo a leitura de Laclau e Mouffe (1985), “oposição real” indica que "A - B" são termos diferentes, cujas positividades existem independentemente da relação que porventura eles possam ter entre si. A "oposição real" ocorre no terreno dos objetos reais (real objects). Como exemplo, os autores apresentam uma hipotética batida entre dois veículos e afirmam: "é claro que um antagonismo não pode ser uma oposição real. Não há nada antagônico numa batida entre dois veículos: este é um fato material que obedece a leis físicas objetivas" (Laclau e Mouffe, 1985 , p. 123).

Já a ideia de "contradição lógica" é representada pela fórmula "A - não A". Segundo essa noção, a relação entre dois termos esgota a realidade de ambos. A "contradição 
lógica" ocorre no terreno das proposições, dos conceitos. Contudo, contradição não redunda em antagonismo, pois "todos nós participamos de uma série de sistemas de crenças mutuamente contraditórios e nenhum antagonismo emerge dessas contradições" (Laclau e Mouffe, 1985, p. 124).

Laclau e Mouffe, após apresentar a diferença entre "oposição real” e "contradição lógica", passam a explicar o que tais categorias têm em comum e o que as faz serem completamente diferentes da noção de antagonismo. Nesse sentido, "oposição real" e "contradição lógica" "partilham algo, o fato de serem relações objetivas, entre objetos conceituais no segundo caso, e entre objetos reais no primeiro. Mas, em ambos os casos, isso é alguma coisa que os objetos já são, a qual faz a relação inteligível" (Laclau e Mouffe, 1985, p. 124; grifos no original). Em outras palavras, os autores afirmam que seja num caso seja no outro, se está diante de positividades, de objetos plenamente construídos, abso154 lutamente prontos e inteligíveis. Assim, estamos falando de "relações objetivas", de “objetos já existentes", de "identidades completas" (cf. Laclau e Mouffe, 1985).

No caso da relação de antagonismo, o que se propõe é algo completamente diferente. Aqui não se fala mais em "relações objetivas", em "objetos já existentes”, em "identidades completas", mas do oposto. Antagonismo indica que “a presença do 'outro' me impede de ser totalmente eu mesmo" (Laclau e Mouffe, 1985, p. 125). Isso quer dizer que, quando se está diante de uma situação desse tipo, deve-se pressupor sempre uma relação entre identidades incompletas, justamente pelo fato de que a relação estabelecida entre ambas é antagônica. Enquanto que, como vimos, a "oposição real" e a "contradição lógica” têm de ser consideradas como sendo relações entre positividades, no antagonismo, os limites da própria objetividade são mostrados, pois o "outro" representa o limite dos sentidos alcançados por determinado discurso, o que quer dizer, em última análise, 
que o antagônico se encontra fora, excluído e limitando a completa positividade daquilo que ele antagoniza.

O status atribuído ao antagonismo é minimizado na obra subsequente a HSS. Assim, em NR, Laclau (1993) rearticula o lugar dessa categoria em seu sistema de pensamento. Se antes antagonismo era entendido como o limite da sistematização do sistema, ou seja, o limite de sentido ao qual o sistema discursivo poderia alcançar tendo em vista a presença do seu corte antagônico, a partir de NR essa categoria perde tal dimensão. Laclau, sobretudo tendo em vista a crítica de Zizek (1993), admite que o antagonismo não pode ser o limite da constituição de sentidos de um sistema, pois que a própria condição do outro antagônico já infere um tipo de simbolização, uma forma de produção de sentidos. Assim, "o que eu não sou" e "contra o que eu me antagonizo" já fazem parte de um sistema de significação. Em uma entrevista para Yannis Stavrakakis (2003, p. 324), Laclau argumenta:

Havia certa ambiguidade na forma como a categoria de antagonismo foi formulada em Hegemony and Socialist Strategy [...] Hoje eu acredito que a constituição do outro como antagônico já pressupõe certa inscrição discursiva - em outras palavras, conceber o outro como um inimigo pressupõe uma identificação a priori de nós mesmos com a posição particular na estrutura da ordem simbólica [isto também pressupõe, em alguns casos, a construção imaginário-fantasmática de ambos os polos antagônicos].É por isso que em meu mais recente trabalho eu movi minha atenção à categoria de "deslocamento" a um nível anterior ao de "antagonismo".

A introdução da categoria de "deslocamento" promove uma mudança importante na teoria do discurso de Laclau. Inicialmente, o autor retira o status privilegiado do antago- 
nismo como o único responsável pela constituição das relações sociais, que permanecem políticas e conflituosas. Antagonismo aparece, a partir de NR, como parte de um sistema de significação, como condição de identificação, como algo simbolizado. O outro antagônico, o inimigo, não é mais o "não simbolizado", mas a própria possibilidade da simbolização, da identificação.

Como já dito, a partir de NR Laclau desenvolve a categoria de "deslocamento" e atribui à mesma uma centralidade no conjunto de noções de compõem a sua teoria. A utilização dessa noção marca claramente o casamento da teoria do discurso com a psicanálise lacaniana. Tal engajamento permite o desenvolvimento da ideia de subjetividade política como alternativa ao deslocamento estrutural. Vejamos tais movimentos.

Primeiramente, acerca do casamento da perspectiva de Laclau com os desenvolvimentos de Lacan, o mesmo já 156 vinha se desenhando desde a década de 1980. Em HSS, por exemplo, as noções de pontos nodais, sutura, articulação já anunciavam essa tendência. No entanto, a introdução da ideia de deslocamento marca uma importante virada teórica. Assim, se em HSS Laclau e Mouffe (1985, p. 107), criticando Foucault, "rejeitam a distinção entre práticas discursivas e não discursivas" afirmando que "cada objeto é constituído como um objeto de discurso, na medida em que nenhum objeto é dado fora de cada condição de emergência discursiva”, a partir de NR a situação muda sensivelmente. Mas em que sentido ela muda?

Segundo Laclau, todo objeto continua sendo um objeto de discurso, tendo em vista que, mesmo que sua existência seja dada por sua materialidade, ela também está marcada pelo contexto de sua constituição. Por exemplo, como já dito aqui, uma bola tem indiscutivelmente a sua existência material, mas a mesma está acompanhada de um contexto simbólico-discursivo. Assim, será uma bola 
de futebol, de basquete, de vôlei, de tênis, dependendo do contexto discursivo ao qual ela está imersa. Nesse sentido, a crítica ao não discursivo foucaultiano permanece a mesma para Laclau. O que muda com a introdução da categoria de deslocamento não é, portanto, o status e o funcionamento da lógica do discurso e da constituição da significação, mas como lidar com uma situação na qual a própria possibilidade de significação chega ao seu limite. O deslocamento é o momento exato da impossibilidade da significação. O deslocamento é o ponto em que Laclau promove o encontro de sua teoria com o real lacaniano ${ }^{10}$. O real lacaniano é justamente o não simbolizado, a impossibilidade da produção de sentidos. Sobre o real em Lacan, Homer (2005, p. 81) argumenta:

A dificuldade de entender o real é parcialmente devido ao fato de que ele não é uma "coisa”; ele não é um objeto material no mundo, ou no corpo humano ou mesmo na "realidade". Para Lacan, nossa realidade consiste de símbolos e de processos de significação. Portanto, o que nós chamamos de realidade está associado com a ordem simbólica ou com a "realidade social". O real é o desconhecido que existe no limite desse universo sociossimbólico e está em constante tensão com ele.

\footnotetext{
${ }^{10}$ Stavrakakis (2003, p. 324) é absolutamente claro nesse aspecto: "o deslocamento, substituindo o antagonismo como central para o político, pode apenas ser entendido como um encontro com o real lacaniano por excelência. Ambos são irrepresentáveis; ambos são ao mesmo tempo traumáticos/interrompidos e produtivos. Deslocamentos são traumáticos no sentido de que 'ameaçam identidades' e são produtivos no sentido de que servem como 'a fundação na qual novas identidades são constituídas'. Similarmente, o real traumático sempre interrompe todas as tentativas de simbolização; e, ainda, ele nunca cessa de chamar por novas simbolizações. Está claro que a emergência desse conceito de deslocamento real como central para o político é um dos mais importantes produtos do diálogo de Laclau com a psicanálise e aquele que diretamente liga o seu argumento sobre a impossibilidade da sociedade com a irredutibilidade do real no discurso lacaniano".
} 
Como dissemos antes, o deslocamento, segundo Laclau, é exatamente o momento do real, ou seja, do desconhecido, da impossibilidade de significação. Se antes Laclau e Mouffe (1985) entendiam esse momento como do antagonismo, o que Zizek corretamente refuta ${ }^{11}$, tendo em vista, como vimos, ser o antagonismo parte do próprio processo de significação, a partir de NR, o momento dessa impossibilidade está representado pela noção de deslocamento.

Assim, pensar determinada estrutura discursiva é pensar num conjunto de sentidos hegemônicos sedimentados que constituem uma determinada ordem. Evidentemente que essa ordem hegemônica pressupõe uma série de antagonismos, tendo em vista que politicamente toda constituição discursiva se, por um lado, é um ato de inclusão de sentidos, por outro lado representa uma série de outras exclusões. Dessa forma, por exemplo, um estado democrático apresenta uma série de características cons158 tituidoras (sufrágio universal, direitos individuais etc.) ao mesmo tempo que pressupõe as suas próprias exclusões (discursos xenófobos, racismo etc.). Evidentemente que não estamos tratando de discursos plenamente constituídos (essencialistas), tendo em vista que os mesmos são sempre passíveis de ressignificações e tais ressignificações refletem a própria validade da noção de hegemonia (para haver hegemonia, deve necessariamente haver contra-hegemonia). Um discurso democrático está sempre ameaçado por práticas não democráticas e a própria ideia de democracia é algo em constante negociação e objeto de incessantes lutas.

\footnotetext{
${ }^{11}$ Zizek (1993, p. 257) percebe essa tentativa dos autores de HSS de dar o status do real lacaniano à noção de antagonismo: "O real conseguiu em Hegemonia se cristalizar no conceito de 'antagonismo social': longe de reduzir a realidade a um tipo de jogo de linguagem, o campo sociossimbólico é concebido como estruturado em torno de certa impossibilidade traumática, em torno de uma fissura que não pode ser simbolizada".
} 
Desse modo, a lógica discursiva, proposta por Laclau e Mouffe (1985), é o resultado de práticas articulatórias que fixam sentidos parciais através de pontos nodais que articulam elementos/momentos. Qualquer constituição discursiva, pensada em termos de sistema discursivo, simboliza, estrutura e reestrutura sentidos, tendo em vista que estamos diante de um processo de constante significação.

O momento do deslocamento é outro. Este ocorre justamente quando a estrutura não consegue processar, semantizar algo novo, algo que, portanto, lhe foge à significação. O deslocamento é, portanto, o encontro com o real, o momento em que o discurso apresenta o seu limite de sentido. Em termos sociopolíticos, uma estrutura deslocada é aquela que experimenta um momento de crise, um momento em que a mesma é posta radicalmente em xeque. O deslocamento é anterior, é externo à significação, portanto, externo ao antagonismo; é uma experiência traumática que desajusta a estrutura, a qual precisa ser recomposta a partir de novos processos de significação. Assim, estamos falando de processos de significação substituindo outros processos de significação, tendo em vista uma falha estrutural provocada pelo deslocamento, ou seja, justamente pela impossibilidade de significação ${ }^{12}$.

Se não podemos alcançar o real, pois o real não é passível de significação, o deslocamento é, portanto, a evidência da incompletude da estrutura, da impossibilidade de sua estruturação final. Se o real é uma instância existente, mas não significável, e se as estruturas estruturam-se a partir de processos

\footnotetext{
${ }^{12}$ No glossário de Jacob Torfing (1999, p. 301) sobre os principais conceitos desenvolvidos pela teoria do discurso, o deslocamento é assim conceituado e exemplificado: "Deslocamento: uma desestabilização de um discurso que resulta da emergência de eventos os quais não podem ser domesticados, simbolizados ou integrados pelo discurso em questão. Por exemplo, a concorrência de inflação e de desemprego no início dos anos 1970 deslocou a ortodoxia keynesiana, a qual basicamente afirmava que a 'estagnaflação' nunca ocorreria. Igualmente, o processo de globalização tende a deslocar a ideia de Estado-nação como o terreno privilegiado para a atividade econômica".
} 
de significação, então, no limite, estamos sempre diante de estruturas incompletas, marcadas pela eterna possibilidade do trauma deslocatório. Numa palavra: são estruturas da falta. É nesse momento de falha na estrutura que o sujeito toma seu lugar de destaque. Conforme Laclau (1993, p. 57), “o lugar do sujeito é o lugar do deslocamento. Portanto, longe do sujeito ser o momento da estrutura, ele é o resultado da impossibilidade de constituir a estrutura como tal - quer dizer, como objetividade". Segundo Howarth (2000, p. 109; grifos no original):

É neste momento de "falha" da estrutura para conferir identidade aos atores sociais que "compele" o sujeito a agir. Nesse sentido, o sujeito não é simplesmente determinado pela estrutura, nem, contudo, ele constitui a estrutura. O sujeito é forçado a tomar decisões [...] quando identidades sociais estão em crise e estruturas necessitam ser recriadas. É no processo dessa identificação que as subjetividades políticas 160 são criadas e formadas.

Num sentido pós-estruturalista, ou seja, em que a estrutura estrutura o sujeito, mas que também é, em certa medida, por ele estruturada, é que existe a resposta ao trauma do deslocamento. A partir de uma estrutura deslocada, gera-se a necessidade de sua reestruturação a partir de novos sentidos ou da reativação de sentidos já existentes. É nesse momento que a categoria de antagonismo assume seu lugar definitivo na teoria do discurso: como parte de processos de significação, de constituição de novas formas de inclusão, mas também de exclusão de sentidos discursivos. Nas palavras de Laclau (1993, p. 57; grifo no original):

[...] a resposta ao deslocamento da estrutura será a recomposição da mesma por parte das diversas forças antagônicas em torno de pontos nodais de articulação precisos. O centramento - a ação de centrar - só é 
possível, portanto, na medida em que há deslocamento e desnivelamento estrutural. Novamente: o deslocamento é a condição de possibilidade e de impossibilidade de um centro.

Assim, o recentramento da estrutura, segundo Laclau, passa necessariamente pela constituição de novos antagonismos e de novos processos hegemônicos. Apesar de antagonismo social ser uma categoria que perde a sua centralidade na teoria do discurso para a de deslocamento, ela é ainda a conditio sine qua non, para Laclau, em relação à possibilidade de existência de discursos.

\section{O limite da normatividade na teoria de Ernesto Laclau}

O normativo, entendido lato sensu como um conjunto de preceitos ou de situações politicamente desejáveis, tem lugar restrito no âmbito da teoria do discurso. Considerando o contexto mais geral do pensamento de Laclau, mesmo com a introdução da categoria de deslocamento substituindo o status privilegiado da categoria de antagonismo, não podemos esquecer que estamos diante de uma perspectiva teórica pós-fundacionalista, ou seja, num constante exercício de questionamento em relação a projetos teóricos que visam se estruturar a partir de um fundamento último, seja ele qual for.

Podemos dizer que essa impossibilidade de encontrarmos um fundamento último está na base ontológica do pensamento político do autor. Todo o seu percurso teórico, de HSS até o seu último trabalho de maior relevância, La razón populista (Laclau, 2005), guarda esta característica essencial: não há como escaparmos do antagonismo, da precariedade e da contingência que dominam as relações sociopolíticas. Tal convicção marca todas as categorias analíticas da teoria do discurso, as quais fundam um sistema de pensamento pós-fundacionalista.

Essa é a razão principal de Laclau ter sido assaz crítico com a tradição marxista, de onde seu próprio pensamento 
sofreu importante influência, sobretudo a partir da vertente althusseriana. Essa é a razão fundamental também para que o autor discorde de soluções políticas deliberativas, fundadas na razão instrumental, na projeção de cenários ideais, artificialmente construídos. O fundamental da crítica laclauniana, seja ao marxismo, seja ao deliberativismo, está no fato de que cada qual, à sua maneira, busca domesticar, dominar os sentidos sociais, quando os mesmos não são passíveis de alcançar um fundamento último. Além disso, Laclau desconfia que soluções desse tipo - que não levam em conta outras possibilidades de equacionar os desafios do mundo político - estejam a um passo de práticas totalitárias.

Uma decisão apodíctica ou, em um sentido mais geral, uma decisão que reivindica para si mesma uma "racionalidade" incontestável, é incompatível com uma pluralidade de pontos de vista. Se a decisão se baseia num raciocínio de caráter apodíctico não é, em absoluto, uma decisão: para uma racionalidade que me transcende e que já decidiu por mim, o meu papel é tão somente o de reconhecer a decisão e as consequências que dela seguem. É por isso que todas as formas de racionalismo radical estão a um passo do totalitarismo (Laclau, 1993, p. 203).

Os discursos que prometem soluções políticas finais e que são construídos com argumentos idealmente interessantes e desejáveis, que prometem novos mundos possíveis, cativam seguidores por duas razões principais. Primeiramente, porque apresentam um conjunto de conceitos, soluções e argumentos retóricos que estão pautados numa genuína vontade de equacionar inúmeras disparidades sociais e políticas. A outra razão se dá justamente com base no que discutimos anteriormente sobre ideologia. Vimos que, para Laclau (1993, p. 106), "o ideológico seria a vontade de 'totalidade' de todo discurso totalizante”. Essa 
vontade está fundada em todos os discursos, mas também em todos os sujeitos por esses interpelados.

A crítica laclauniana acerca de propostas normativas não ocorre obviamente pelo fato de que as mesmas sejam em si "incorretas" ou mesmo inviáveis. O ponto fundamental da crítica reside justamente porque as mesmas devem ser percebidas sempre no plano ôntico, o que invariavelmente significa que são decisões políticas tomadas num campo marcado pela indecidibilidade. Isso quer dizer que nunca uma proposta normativa será capaz de dominar todos os sentidos sociais, de eliminar todos os antagonismos existentes. Todas as decisões, para serem efetivamente decisões, como expresso na citação acima, necessitam habitar num mundo indecidível, ou seja, marcado pela miríade de possibilidades de ocorrência de outras decisões. Uma decisão apodíctica, nesse sentido, não é uma decisão, mas uma tentativa sempre ineficaz de fechar todas as demais propostas normativas que a contingência do mundo possibilita. Nesse caso, estamos a um passo de um desejo totalitário.

Dito isso, como é possível pensar o normativo tendo como pressuposto a teoria do discurso? Antes de propriamente tentarmos responder essa pergunta, é preciso fazer uma observação. No início do texto, apresentamos Laclau como um teórico político, no sentido de que seus trabalhos buscam explicar, num nível ontológico, a lógica do fenômeno político e, ao mesmo tempo, propor cenários normativos. Entretanto, o autor tem sempre no horizonte a noção de que todas as ações políticas, todas as suas decisões, estão sempre marcadas pela precariedade e pela contingência. Tais características estão presentes, por exemplo, em todas as noções apresentadas neste artigo. Elas servem para dizer mais ou menos o seguinte: tudo bem, vocês podem pensar normativamente o que vocês quiserem, mas toda decisão política ocorre sempre no plano ôntico e está, portanto, marcada por sua própria finitude diante da ontologia do político. A ideo- 
logia, o antagonismo, a disputa em torno do sentido do ser da existência, os eventos de deslocamento estrutural não são erradicáveis simplesmente por desejos normativos. São, pelo contrário, inerradicáveis enquanto existir o mundo político.

A percepção laclauniana acerca da finitude da decisão ôntica, no sentido de que a fixação completa de sentidos sempre nos escapa diante da infinitude do social, está na base da crítica desse autor, por exemplo, à tradição habermasiana. Em resposta à Aletta Norval, autora que busca articular uma teoria política normativa a partir dos enfoques deliberativos e pós-estruturalistas ${ }^{13}$, Laclau (2008b, p. 369) apresenta claramente a distinção entre o ontológico e o ôntico, além de demonstrar a limitação teórica de tomar o primeiro pelo segundo.

Agora estou em condições de responder à crítica de Norval quando ela diz que, em minha análise, tenho descuidado a 164 questão dos arranjos institucionais democráticos e que isso se deve à ênfase exclusiva que ponho no aspecto ontológico da questão e a minha concomitante falta de atenção aos aspectos ôntitcos. Minha resposta é que uma teoria geral da democracia só pode especificar suas dimensões constitutivas, mas deve ser muito cautelosa com respeito à articulação institucional das mesmas. Precisamente porque é uma questão histórica contingente, essa articulação não pode ser determinada no nível de uma teoria geral da democracia. Tentar que se leve a cabo essa determinação no interior de uma teoria geral produziria resultados opostos aos que Norval pretende alcançar, quer dizer, a transformação de um arranjo ôntico particular em uma categoria ontológica. Essa é a melhor receita para terminar num etnocentrismo e num essencialismo sociológico.

\footnotetext{
${ }^{13}$ Para uma apresentação da teoria aversiva de Aletta Norval, ver o artigo de Mendonça (2010).
} 
Diante do quadro apresentado na citação anterior, as expectativas normativas que se abrem a partir da teoria do discurso não podem ser vistas stricto sensu como no caso dos enfoques deliberativos. Se não se pode tomar o ontológico pelo ôntico, todas as experiências políticas reais são necessariamente sempre limitadas e rodeadas pela precariedade e pela contingência histórica. Isso quer dizer que o normativo depende do seu momento de ocorrência e é diferente de situação para situação. Ele não pode ser concebido a priori, fora do seu contexto de emergência.

O normativo, portanto, aparece aqui com um grau praticamente irrestrito de liberdade. Por um lado, porque não podemos falar num sujeito político privilegiado, como no caso do proletariado da tradição marxista; por outro, porque as possibilidades normativas mesmas são múltiplas, uma vez que estão diretamente relacionadas com a ocorrência das situações políticas concretas. Entretanto, esse enfoque teórico também leva em consideração a possibilidade para o retrocesso de avanços políticos, justamente pelo fato de que as possibilidades de mudanças políticas são múltiplas. Por exemplo, os avanços civis conquistados pela luta feminista no século XX não são conquistas para todo o sempre: estão sempre rodeados pela ameaça do retrocesso.

Os sujeitos políticos ecológico e feminista, por exemplo, são até certo ponto, como qualquer outra identidade social, significantes flutuantes, e é uma ilusão perigosa pensar que eles estão seguros de uma vez por todas, que o terreno que constituiu suas condições discursivas de emergência não pode ser subvertido (Laclau e Mouffe, 1985, p. 141; grifo no original).

Segundo a teoria do discurso, a única forma de garantir avanços políticos consistentes está na constante renegociação entre identidades articuladas em discursos hegemônicos. Nesse caso, e tomando como exemplo a citação anterior, os 
sujeitos políticos ecológico e feminista devem articular suas demandas identitárias com outros sujeitos políticos em torno de discursos hegemônicos, capazes de assegurar ao máximo suas conquistas alcançadas e, em conjunto com outras demandas por mais inclusão social, promover movimentos estratégicos de maneira a avançar politicamente ainda mais. No entanto, não existem receitas normativas eficazes de ser estipuladas antes da situação política dada: tudo depende do contexto de emergência das próprias demandas políticas. Assim, não há fórmulas político-normativas prontas; não há um mundo para ser inventado antes da sua própria ocorrência. É nesse sentido que Laclau é um teórico político. Ele não acredita que a teoria deva estar desconectada da prática política, uma vez que a primeira está a serviço da segunda.

\section{Daniel de Mendonça}

é professor do Instituto de Filosofia, Sociologia e Política da 166 Universidade Federal de Pelotas, RS.

\section{Bibliografia}

ALTHUSSER, L. 1985. Aparelhos ideológicos do Estado. Rio de Janeiro: Graal. COLLETTI, L. 1975. "Marxism and the dialectic". New Left Review, v. I, n.

93, Sept./Oct. pp. 1-29.

HOMER, S. 2005. Jacques Lacan. New York: Routledge.

HOWARTH, D. 2000. Discourse. Buckingham: Open University Press.

LACLAU, E. 1993. Nuevas reflexiones sobre la revolución de nuestro tiempo.

Buenos Aires: Nueva Visión.

. 1994. "Introduction". In: LACLAU, E. (ed.). The making of political

identities. London: Verso.

. 1996. Emancipación y diferencia. Buenos Aires: Ariel. 2000. Misticismo, retórica y política. Buenos Aires: Fondo de Cultura

Económica.

. 2005. La razón populista. Buenos Aires: Fondo de Cultura Económica. . 2008a. "Atisbando el futuro". In: CRITCHLEY, S.; MARCHART, O.

(orgs.). Laclau: aproximaciones críticas a su obra. Buenos Aires: Fondo de

Cultura Económica. 2008b. "Posfácio". In: MENDONÇA, D.; RODRIGUES, L. P. (orgs.). 
Pós-estruturalismo e teoria do discurso: em torno de Ernesto Laclau. Porto Alegre: EdiPUCRS.

LACLAU, E.; MOUFFE, C. 1985. Hegemony and socialist strategy: towards a radical democratic politics. London: Verso.

. 1993. "Posmarxismo sin pedido de disculpas". In: Nuevas reflexiones sobre la revolución de nuestro tiempo. Buenos Aires: Nueva Visión.

MARCHART, O. 2007. Post-foundational political thought: political difference in Nancy, Lefort, Badiou and Laclau. Edinburgh: Edinburgh University Press.

2008. "La política y la diferencia ontológica. Acerca de lo ‘estrictamente filosófico’ en la obra de Laclau”. In: CRITCHLEY, S.;

MARCHART, O. (orgs.). Laclau: aproximaciones críticas a su obra. Buenos Aires: Fondo de Cultura Económica.

MARX, K.; ENGELS, F. s/d. A ideologia alemã. Vol. I. Editorial Portugal/ Brasil, Presença/Livraria Martins Fontes.

MENDONÇA, D. 2010. "Para além da deliberação? Apontamentos sobre a normatividade da teoria pós-estruturalista da democracia radical". Mediações, Revista de Ciências Sociais, v. 15, n. 2, pp. 99-125.

; RODRIGUES, L. P. 2008. Pós-estruturalismo e teoria do discurso: em torno de Ernesto Laclau. Porto Alegre: EdiPUCRS.

NORVAL, A. 2007. Aversive democracy: inheritance and originality in the democratic tradition. Cambridge: Cambridge University Press.

PORTINARO, P. 2007. El realismo político. Buenos Aires: Ediciones Nueva Visión.

RODRIGUES, L. P.; MENDONÇA, D. 2006. Ernesto Laclau e Niklas Luhmann: pós-fundacionismo, abordagem sistêmica e as organizações sociais. Porto Alegre: EdiPUCRS.

STAVRAKAKIS, Y. 2003. "Laclau with Lacan: comments on the relation between discourse theory and Lacanian psychoanalysis". In: ZIZEK, S. (ed.). Jacques Lacan: critical evaluations in cultural theory. Vol. III: Society, Politics, Ideology. London: Routledge.

TORFING, J. 1999. New theories of discourse: Laclau, Mouffe and Zizek. Oxford: Blackwell.

ZIMERMAN, D. E. 2001. Vocabulário contemporâneo de psicanálise. Porto Alegre: Artmed.

ZIZEK, S. 1993. "Más allá del análisis del discurso". In: LACLAU, E. Nuevas reflexiones sobre la revolución de nuestro tiempo. Buenos Aires: Nueva Visión. . 2005. El sublime objeto de la ideología. Buenos Aires: Siglo Veintiuno. 


\section{O LIMITE DA NORMATIVIDADE NA TEORIA POLÍTICA DE ERNESTO LACLAU}

\section{DANIEL DE MENDONÇA}

Resumo: O presente trabalho consiste num esforço analítico que pretende refletir sobre o terreno da normatividade em teoria política baseada na ontologia política presente na teoria do discurso de Ernesto Laclau. Nesse sentido, nosso objetivo principal é discutir criticamente as possibilidades normativas para a teoria política em geral a partir de uma teoria política pós-fundacional específica. Partimos da discussão que estabelece que o pensamento político de Laclau deve ser tomado de um ponto de vista teórico e não como uma abordagem de filosofia política. Isso supõe uma aplicabilidade analítica, baseada em práticas políticas reais, que pode ser útil (com todas as limitações existentes como iremos explorar neste texto) para pensar sobre normatividade na política. Exploramos, a seguir, as noções de Laclau de ideologia e discurso, antagonismo e deslocamento. A partir da análise desses conceitos, estabelecemos os limites para se pensar a normatividade na teoria política de acordo com a teoria do autor.

Palavras-chave: Pós-Estruturalismo; Pós-Fundacionalismo; Teoria do Discurso; Normatividade; Ernesto Laclau.

\section{THE LIMIT OF NORMATIVITY IN ERNESTO LACLAU'S POLITICAL THEORY}

Abstract: The present work consists in an analytical effort in order to reflect on the normativity terrain in political theory from the political ontology presents in Ernesto Laclau's discourse theory. In this sense, our main purpose is to critically discuss the normative possibilities for the political theory in general from a specific postfoundational political theory. We depart from a discussion, which establishes that Laclau's political thought should be seen from a 
theoretical point of view and not as political philosophy enterprise. This supposes an analytical applicability based on actual political practices that can be useful (with all limitations as we shall explore in this text) to think about normativity in politics. The next steps toward our main purpose are to explore Laclau's notions of ideology and discourse, antagonism and dislocation. Thereafter exploring these concepts we are able to establish the limits to think normativity in political theory according to the author's theory.

Keywords: Post-Structuralism; Post-Foundationalism; Discourse Theory; Normativity; Ernesto Laclau. 